\title{
Research on the Application of Accounting Tools of Integrated Management of Business Finance under the Background of Supply-Side Reform
}

\author{
Qian Gao \\ ShengLi College China University of Petroleum; Dongying 257000, Shandong Province, China.
}

\begin{abstract}
With the arrival of the new normal of China's economy, enterprise scale is no longer the basic goal of enterprise development. In order to improve the operating efficiency and core competitiveness of enterprises, the Chinese government has put forward the working idea of supplyside structural reform. In order to meet the requirements of the mode of refined management and diversified operation of enterprises, there are two major problems in the financial management of enterprises that need to be solved urgently. On the other hand, enterprises do not have a unified master data management strategy. Therefore, this paper puts forward basic guiding ideas from the perspective of establishing financial business integration information system: strategic planning takes "applicable" + "supporting" as the principle, business management takes "rules" + "process" as the means, and system support takes "moderate" + "flexible" as the goal. Enterprises should take strategic layout, business process, information standards and other aspects into consideration, and gradually establish and use the integrated financial business management system to realize the double improvement of management quality and efficiency.
\end{abstract}

Keywords: Supply-side reform; Financial business integration; Enterprise management system.

\section{Development Background and Significance of Business and Financial Integration}

Under the working thought of supply-side structural reform, enterprises no longer blindly pursue the blind expansion of operation scale, and then turn to the pursuit of refinement, differentiation and diversified operation. Under the new economic situation and competition situation, more and more enterprises have adopted multi-business and multi-plate operation. Many traditional enterprises are also becoming internet-oriented. Multi-business operation mode and Internet mode have become an economic trend. More and more industries are beginning to mature. Many enterprises no longer only pursue production scale, they start to use fine management to improve efficiency and increase corporate profits. With the change of business pattern and the acceleration of competition rhythm, the primary obstacle facing by the enterprise's fine management is the disconnection between finance and business. This problem is reflected in that enterprises cannot achieve the predicted performance as promised directly and the reason cannot be found in time either. Managers can't quickly understand what the cost of a business is by looking at its accounts. The management of an enterprise cannot evaluate the strategic investment effect in the business field. Enterprise managers are unable to understand the costs and benefits of enterprise internalization clearly. "Business financial integration" is indeed the primary task of traditional enterprises in the context of Internet.

The core goal of business financial integration is to establish a "mapping" relationship between financial and business operations. That is, how to find problems from the financial perspective, how to timely and accurately interpret the problems in business operations. It is a way to understand the relationship between business and financial data. It combines data analysis with business requirements.

The integration of business finance is based on the premise that modern enterprise management is decomposed layer by layer from strategy to information system. Successful and sustainable enterprises have clear and concise corporate strategies. They form the core of business operation around this strategy, namely product or service strategy. These strategies include budgeting and performance programs, and setting financial accounting mechanisms, organizations, processes, and rules. These formed the operation mechanism and structure of the enterprise. The operation mechanism is supported by the information system to ensure the implementation of product strategy. 
The enterprise information island we usually refer to is actually the problem of data unobstructed and inconsistent in this path. Business financial integration is the process of finding the pain point along this path and solving it by information means.

\section{Major Management Accounting Tools for Business and Financial Integration}

This paper mainly discusses what kind of tools we should adopt to perfectly combine business management and financial management. This paper mainly discusses what kind of tools we should adopt to combine business management and financial management perfectly. The author thinks that it is difficult to realize the integrated management of financial services with independent financial instruments. Only under the logical framework of enterprise strategic management can the integrated management of financial business be realized by combining management accounting tools and business management tools. The main tool of business financial integration is structured enterprise information management system. Enterprise information management system includes OA system which mainly manages administration and personnel, CRM system which manages sales customer information, MEMS managing product development, raw material purchasing, as well as production planning, and FMS which managing financial affairs of enterprise. Under the background of supplyside reform, enterprise management becomes more and more complex, and any independent tool is more and more difficult to be qualified for the important task of integrated management. In enterprise management, the combination of these tools is collectively referred to as ERP of enterprise resource management system.

The concept of Enterprise Resource Planning was proposed by Gartner consultants and research institutions in the early 1990s, i.e., Enterprise Resource Planning. At present, ERP system tries to solve the core business problems of enterprises in supply and marketing, finance, planning, quality and manufacturing comprehensively. Its significance lies in integrating the overall business management of enterprises with the best management resources as the starting point and maximizing the operating efficiency of enterprises.

The essence of ERP is an enterprise information management system. As a tool, it combines information technology and business processes, serving every business department and providing good information, storage and computing services. A good ERP system can perfectly combine the business process and financial process of an enterprise. The design concept of ERP fully reflects the integration of financial services. Every enterprise is unique, It adapts different strategies, different management modes, different business processes. No ERP system can be applied to every enterprise. Most large enterprises need to build their own ERP management system. But when building these systems, companies often run into problems.

\section{Major Problems Faced By Enterprises When Establishing Integrated Information System for Financial Services}

At present, there are typical and common problems in almost all the key links of product management, accounting logic, assessment mechanism, system architecture, data management, IT control and business requirements.

\subsection{The Business Process Is Chaotic and the Financial Process Does Not Match the Business Logic}

After the diversification of business, the enterprise's process standardization has been reduced to a relative low level. At the same time for different businesses in the details of the processing link, the enterprise did not form a common process. The core reason of this problem is that most enterprise transformation adheres to the customer-oriented principle and management strategy. Therefore, they ignore the standardization and standardization of their product and service system design and management. Second, with the advent of the Internet and big data era, the pace of enterprise marketing 
is accelerated. Many enterprises have added too many concepts of marketing, channel and sales management in product management. They confuse product process management with customer marketing.

Due to the above problems, many enterprises have chaotic business processes. This results in a mismatch between the financial workflow and the business logic. This first shows in the enterprise affairs financial affairs management. Many enterprises do not have clear rules in the management of financial accounts and business accounts; management of the financial accounting unit is not scientific. In many cases, it is confused with the organizational structure, and there is no effective management mechanism that inherits and differentiates from the organization. In addition, there is no business type code set below the subject level, or the business type code set is unreasonable, and so on. Accounting system should be the core of business and financial connection. However, because of the above problems, the construction of financial accounting system lags behind for a long time. This becomes the most easily ignored part of the business system. The financial system itself only observes economic results from an accounting perspective. If the financial system does not match the business logic, there will be an inaccurate and untimely financial data response. Due to the chaotic accounting system, it is not clear what accounting information is required. Business ledger records and statistical statements also ignore the information elements required for financial accounting. Therefore, there is no way to form a financial process system that matches the business logic.

\subsection{There Is No Unified Master Data Management Strategy}

Many enterprises are weak in the construction of business systems. There is no systematic management thought for the development of information management system. This leads enterprises to develop information management system vertically in order to adapt to the business development. These systems support a product or business, and each product or business is independently accounted for. This leads to the inconsistency of the same analysis object or subject in different systems and the inconsistency of various accounting rules. These enterprises do not have a master data management strategy, and the system does not have the reverse constraint of business process standardization. In the process of business system construction, these enterprises often do not have the ideas and methods of master data management, nor do they have the correct master data management strategy. Due to the disunity of Data standards, the accuracy of the data is naturally difficult to ensure. Companies can't make the right judgments and decisions.

Due to the lack of data standards and model specifications for the construction of business systems, the financial information management system of enterprises often has quality problems and cannot restore business logic. Data standards and model specifications are considered optional or irrelevant in most business system development. Although we need to balance enterprise size and development standardization. If enterprises ignore data standards and norms all the time, it will not only cause huge repair costs after problems, but also hinder the normal construction of enterprise business system. Specifically, in the system development stage, developers did not define the enterprise's basic data standards, especially the standard system of common code, and the development efficiency was low. There is no logical data model for abstract enterprises, so there is no reasonable guidance for enterprise data organization. The lack of an enterprise data model specification results in the design level of each system depending on the technical capabilities of the developers. In the long run, the enterprise IT department is completely helpless in the face of system problems or upgrades.

\section{Guiding Ideology for the Application of Financial Business Integrated Management System}

\subsection{Strategic Planning: "Applicable" + "Supporting"}

The integrated management system of enterprise affairs and financial affairs is established around the strategic layout and planning of enterprise development. Enterprise strategic transformation, first of all, needs to combine the current business situation, not cross the boundary blindly. The 
formulation of new strategic goals needs to consider their own capabilities and breakthrough methods. In terms of strategic concept analysis, the author believes that the most effective methodology and tools are situation analysis, i.e., "SWOT". And, more importantly, when a strategy is been launched, at the same time, a complete set of organizational adjustment plan, business mode, the principle of financial accounting, investment and strategy will be needed, especially to synchronize supporting information system, because the larger the new strategic investment is, the more need to be able to timely data read from a financial business problem, thus the corresponding correction and adjustment. These supporting requirements actually mean that the promulgation of the strategy requires a set of basically mature business management methods and information support plans.

\subsection{Business Management: "Rules" + "Processes"}

Whether new business or traditional business, the integration of business finance should start from the definition of responsibility, power and interests of all activities in the whole life cycle of business development.

Step 1: sort out the basic business process and decompose the process.

Step 2: model the business process. One of the most effective methods is to normalize, standardize and digitize the core business management process through 5W1H decomposition.

Step 3: define the accounting logic of business process. Accounting is the record of economic activities of enterprises. How to clearly reflect various economic activities into financial data in accordance with accounting standards and financial systems of enterprises, and to help management and investors understand the business development from the perspective of financial analysis and strategic investment is the core of business financial integration.

Step 4: set the flow rules for the business in accordance with the process implementation.

Step 5: reasonably evaluate the enterprise organizational structure and system support capability for the business process development, as well as subsequent improvement Suggestions; need to design a process form that does business by hand without the support of an information system.

Step 6: establish the means, rules and methods for the statistics and evaluation of the business status and financial status, and clarify the frequency, mechanism and responsibility of the data collection and processing involved.

\subsection{System Support: "Moderate" + "Flexible"}

After we have sorted out the business management methods, the enterprise information system will accompany the whole process of business development. At present, especially under the general trend of "Digital" transformation, information system has become the basic life support of enterprise operation. System construction and transformation need to consider the following:

Does the business really need system support, or does it need system support in the short term according to the business volume? Does this business need new systems?

Due to the departmental boundaries, some organizations always regard the system as their own departmental property, and this leads to the repetitive system construction of similar bisiness. In this way, the burden on the IT department will be heavier and heavier. If business can be carried out on the basis of the appropriate transformation or adjustment parameters of the original system, that is, the basic support, enterprises should try not to build new systems. The optimization and adjustment of the original system should follow the principles of enterprise architecture. Historical system adjustment needs enterprises have strong ability of architecture management, especially the "application architecture" and "data structure" the ability of management, need to have IT architecture "platform", "modular", "the transition parameters can be configured", "process rules drive", "service IT capability" and other basic enterprise IT architecture thought and theory as the guiding principle. A good architecture allows enterprise IT to be "flexible", "efficient" and "low cost". Good architecture cultivation is the accumulated experience of enterprise IT personnel from long-term practice.

Within a reasonable architecture, we can pursue the concept of "big data and mobile connectivity," which is a technical means of implementation, not an architectural principle. The application of these 
technologies can improve the system's interaction friendliness and the efficiency of business operation.

\section{Conclusion}

To sum up, under the background of supply-side reform, diversified development modes and refined operation and management modes of enterprises all put forward higher requirements for the integration of corporate affairs and financial services. Enterprises should take strategic layout, business process, information standard and other aspects into consideration in the process of building their own financial integrated management tools. In this way, enterprises can gradually establish a unified financial business integrated management system.

\section{Acknowledgements}

1). The Social science planning research project of Shandong Province: "The research on the integration and innovation between Amoeba model and management accounting of petroleum equipment manufacturing industry" (NO.: 17CKJJ04).

2). The Human and social science research project of Shandong Provincial Education Department: "The research on competitiveness improvement driven by supply-side reform in the petroleum equipment manufacturing industry in the Yellow River delta region" (NO.: J17RB123).

3). The Chun Hui project of ShengLi College China University of Petroleum: "The research on the integration and innovation of management accounting tools which boost the new economic momentum from the perspective of "Business finance integration" (NO.: KY2018008).

\section{References}

[1]. Yang Lu. Practical analysis of business and financial integration [J]. Chief accountant of China, 2015(11):90-91.

[2]. Zhou Li. Introducing the concept of management accounting to promote the integration of business finance -- reflections on the integrated accounting of financial business in tobacco leaf [J]. Commercial accounting, 2015 (23): 99-100.

[3]. Yan Jun. Discussion on business and financial integration of management accounting application [J]. Business, 2016 (15): 140.

[4]. Tang Tao. Optimization Study on the A Research Institute of AIS Based on the Integration of Financial and Business [D]. Chongqing: Chongqing University of Technology, 2017(18):45.

[5]. Hong Mei. A preliminary study on management accounting based on "business and financial integration" -- taking the practice of J Company as an example [J]. Chief accountant of China, 2016 (09): 61-63.

[6]. Zhou Shines. The control based on the integration of business and financial with TQ Company as an example [D]. Guangdong: Guangdong University of Finance \& Economics, 2017(4):3. 